\title{
MONITORING THE STATOR CURRENT IN INDUCTION MACHINES FOR POSSIBLE FAULT DETECTION: A FUZZY/BAYESIAN APPROACH FOR THE PROBLEM OF TIME SERIES MULTIPLE CHANGE POINT DETECTION
}

\author{
Marcos F.S.V. D'Angelo ${ }^{1 *}$, Reinaldo M. Palhares ${ }^{2}$, \\ Renato D. Maia ${ }^{1}$, João B. Mendes ${ }^{1}$, Petr Ya. Ekel $^{3}$, \\ Camila K.S. Cangussu ${ }^{1}$ and Lucas A. Aguiar ${ }^{1}$
}

Received January 27, 2016 / Accepted May 18, 2016

\begin{abstract}
This paper addresses the problem of fault detection in stator winding of induction machine by a multiple change points detection approach in time series. To handle this problem a new fuzzy/Bayesian approach is proposed which differs from previous approaches since it does not require prior information as: the number of change points or the characterization of the data probabilistic distribution. The approach has been applied in the monitoring the current of the stator winding induction machine. The good results obtained by proposed methodology illustrate its efficiency.
\end{abstract}

Keywords: Fuzzy/Bayesian, multiple change points detection, fault monitoring.

\section{INTRODUCTION}

Fault detection and analysis is a very important strategy that is commonly employed in the industry with the purpose of allowing a cost-effective maintenance policy, keeping productivity standards and ensuring safety. The fault analysis gives support for the design of corrective actions, system redundancies, and safety policies in order to mitigate the effects of a fault [33]. A fault diagnosis procedure is typically divided into three tasks:

i) fault detection, indicating the occurrence of some fault in a monitored system;

\footnotetext{
*Corresponding author.

${ }^{1}$ Universidade Estadual de Montes Claros - UNIMONTES, Departamento de Ciência da Computação, Av. Rui Braga, s/n, 39401-089 Montes Claros, MG, Brasil. E-mails: marcos.dangelo@unimontes.br; renato.dourado@unimontes.br; joao.mendes@unimontes.br; camila@engenhariadesistemas.com; lucas@engenhariadesistemas.com

2 Universidade Federal de Minas Gerais, Departamento de Engenharia Eletrônica, Av. Antônio Carlos, 6627, Pampulha, 31270-901 Belo Horizonte, MG, Brasil. E-mail: rpalhares@ufmg.br

${ }^{3}$ Pontifícia Universidade Católica de Minas Gerais, Programa de Pós-Graduação em Engenharia Elétrica, Av. Dom José Gaspar, 500, 30535-610 Belo Horizonte, MG, Brasil. E-mail: ekel@ pucminas.br
} 
ii) fault isolation, establishing the type and/or location of the fault; and

iii) fault identification, determining the magnitude of the fault.

After a fault has been detected and diagnosed, in some applications it is required that the fault be self-corrected, usually through controller reconfiguration. This is usually referred to as fault accommodation.

The literature presents several classes of strategies to deal with fault detection and isolation (FDI) [14]. These strategies can be, in general, divided in approaches based on quantitative models [68] and on qualitative models [66], [67].

Most of the quantitative model-based approaches are based on the knowledge of mathematical models of the plant. Many survey papers with different emphasis on various model-based approaches have been published over the past years. The main approaches in this context are based on (unknown input) observers [14], [15], [16], [52], [62], [63], parity relations [14], [50] and Kalman or robust filters [1], [14], [28], [29], [72]. The requirement of a mathematical model of the plant can lead to several difficulties in the implementation of these approaches, for instance due to factors such as system complexity, high dimensionality, nonlinearities and parametric uncertainties.

On the other hand, most of the qualitative model approaches are based on some pattern analysis of the historical process data. The main related approaches are: signed directed graph [5], [13], [47], fault tree [23], fuzzy systems [18], [25], [54], qualitative trend analysis [20], [22], [26], [48], mutual information [69], neural networks [12], [17] (neural networks also can be used as observer [64], [51]), artificial immune systems [43], [44], [57], Bayesian networks [65], [70] and the combination of techniques [19], [38].

In this paper, a new quantitative approach for fault monitoring is presented. This new approach is based on a fuzzy/Bayesian representation and was extended to the detection of multiple change points, not just one or two change points as in [20] and [46], respectively. To illustrate the efficiency of the proposed methodology, the problem of monitoring the stator current of induction machine, for possible fault detection, has been solved.

Induction motors are the most important electric machinery for different industrial applications. Faults in the stator windings of three-phase induction motor represent a significant part of the failures that arise during the motor lifetime. When these motors are fed through an inverter, the situation tends to become even worse due to the voltage stresses imposed by the fast switching of the inverter [11]. From a number of surveys, it can be realized that, for the induction motors, stator winding failures account for approximately $30 \%$ of all failures [2], [34].

The stator winding of induction machine is subject to stress induced by a variety of factors, which include thermal overload, mechanical vibrations and voltage spikes. Deterioration of winding insulation usually begins as an inter-turn short circuit in one of the stator coils. The increased heating due to this short circuit will eventually cause turn to turn and turn to ground faults which finally lead the stator to break down [60]. 
Although there is no experimental data that indicate the time delay between inter-turn and ground insulation failure, it is believed that the transition between the two states is not instantaneous. Therefore, early detection of inter turn short circuit during motor operation can be of great significance as it would eliminate subsequent damage to adjacent coils and the stator core, reducing repairing cost and motor outage time [6], [59].

However, early stages of deterioration are difficult to detect. In general, most of the previous references present approaches for dealing with abrupt faults in the stator winding, which are easier to be detected than incipient faults. In spite of these difficulties, a great deal of progress has been made on induction machine stator-winding incipient fault detection. Methods that use voltage and current measurements offer several advantages over test procedures that require machine to be taken off line or techniques that require special sensors to be mounted on the motor [58]. Other methods, in the context of fault related to the stator-winding, can be found in [9], [10], [24], [53], [61]. There exist other type of approaches to deal with different faults in induction machine, unlike the one considered in this paper, as, for example, dynamic eccentricity, unbalanced rotors, bearing defects and broken rotor bars (see [56] for details and further references).

This paper is organized as follows. Section 2 shows the new fuzzy/Bayesian approach. Section 3 presents and analyzes the induction machine modeling considering the case of turn-to-turn short circuit in stator winding and shows the results for monitoring stator current of induction machine. Finally, section 4 presents the concluding remarks.

\section{FUZZY/BAYESIAN APPROACH FOR MULTIPLE CHANGE POINTS DETECTION}

Traditional methods of building models for time series are based on statistical techniques, aiming to select models that satisfactorily explain its dynamic behavior. However, some questions can be raised:

- There is regime change in the series?

- Can a single model to portray this dynamic for the whole data set?

If there are significant changes in the time series, it seems natural to find turning points before the entire modeling process. There are several papers approaching the problem of detecting points of change, as in financial series [49], ecological series [7], crime rate [41], fault detection [20], [22], etc. The main techniques for change points detection presented in the literature are based on statistical tests and Bayesian analysis. The most common statistical test in change points detection problem is the CUSUM and in the context of Bayesian analysis are widely used the MCMC methods. The CUSUM test proposed by [31] is widely used in detecting change points. Some applications, modifications and extensions of this method can be seen in [32], [42], and [45]. The context of Bayesian analysis has as a reference [4], which uses a partition product model (MPP) for identifying points of change in the average data with a normal distribution. In [39], the posteriori probability of a time to be a turning point is used as a measure of evidence that the behavior of a data sequence has changed at some point. In [40], the effectiveness of the measure 
is evaluated in identifying changes, proposed by [39], in the rate of the Poisson distribution in sequentially observed data, and a comparison being done with the one proposed by [30]. However, all these researches require some a priori knowledge of the statistical behavior of the time series, for example, what type of distribution represents better its dynamic behavior. In this work, an approach that is independent of such a priori knowledge about the time series will be used, considering the empirical demonstration presented in [20] that series, after being transformed using fuzzy operations, can be adequately approximated by series with beta distribution. Thus, the parametrization of the beta distribution is used to replace a priori knowledge about the time series. Moreover, the method was extended to the detection of multiple change points, not just one or two change points as in [20] and [46], respectively.

\subsection{Time Series Transformation by Fuzzy Sets}

The fuzzy set theory, proposed by [71], has received much attention recently, not only in the context of theoretical developments, but also in applications. One of its main applications is in clustering methods, whereas classical methods of grouping the data into $k$ separate categories, and in many cases some elements may not belong to a specific category, belonging to two or more categories simultaneously. Using fuzzy clustering methods is a good way to solve this problem because, unlike the classical approach, an element can belong to more than one category simultaneously.

Below it's proposed an alternative quantization of a time series, through fuzzy clustering, for use in the Metropolis-Hastings algorithm.

Definition (Fuzzy Clustering): Let $y(t)$ be a time series, and consider a positive integer $k$. Define the set $C=\left\{C_{i} \mid \min \{y(t)\} \leq C_{i} \leq \max \{y(t)\}, i=1,2, \ldots, k\right\}$ such that it solves the minimization problem:

$$
\min \sum_{i=1}^{k} \sum_{\mu_{i}(t) \in C_{i}}\left\|\mu_{i}(t)-C_{i}\right\|^{2},
$$

so $C=\left\{C_{i}, i=1,2, \ldots, k\right\}$ is the set of centers of the time series $y(t)$. In (1),

$$
\mu_{i}(t) \triangleq\left[\sum_{j=1}^{k} \frac{\left\|y(t)-C_{i}\right\|^{2}}{\left\|y(t)-C_{j}\right\|^{2}}\right]^{-1}
$$

is the fuzzy membership degree of $y(t)$ for each center $C_{i}$.

Notice that, given a set $C$ of cluster centers, it is an easy task to measure the distance of each point in the time series $y(t)$ to each center $C_{i}$. The problem of finding the centers can be solved, for instance, via K-means [36], C-means [3], or Kohonen network [35], and in all these approaches, prior knowledge of the number of groups is needed, a fact that justified the use of an adaptive algorithm, where this information is not required. The optimization of the Average Silhouette Width, initially proposed by [55], was used in this paper. 
For illustration purposes, in this paper, the time series (3) is used:

$$
f(t)=\left\{\begin{array}{ll}
p_{1}+0.1 * \varepsilon(t)-0.1 * \varepsilon(t-1), & \text { if } t \leq m_{1} \\
p_{2}+0.1 * \varepsilon(t)-0.1 * \varepsilon(t-1), & \text { if } m_{1}<t \leq m_{2} ; \\
\vdots & \\
p_{k}+0.1 * \varepsilon(t)-0.1 * \varepsilon(t-1), & \text { if } t>m_{k-1} .
\end{array}\right\}
$$

being $p_{1}$ the first operation point, $p_{2}$ the second operation point, $p_{k}$ the $k-t h$ operation point, $\varepsilon(t)$ a noise with distribution $\pi\left(\right.$.) in the instant $t$, and $m_{i}$ the change points.

Figure 1 illustrates the time series (3) with $p_{1}=1, p_{2}=2, p_{3}=3, p_{4}=4, p_{5}=5, m_{1}=30$, $m_{2}=60, m_{3}=90, m_{4}=120$ and $\varepsilon(t) \sim U(0,1)$ for 150 observations of the time series, Figure 2 shows the centers of time series and the membership degrees $\mu_{i}(t)$ is illustrated by Figure 3. Note that the first and last membership degrees have a single change, which will be identified using the approach proposed by [20], and the intermediate membership degrees have two changes to be identified by the approach proposed by [46].

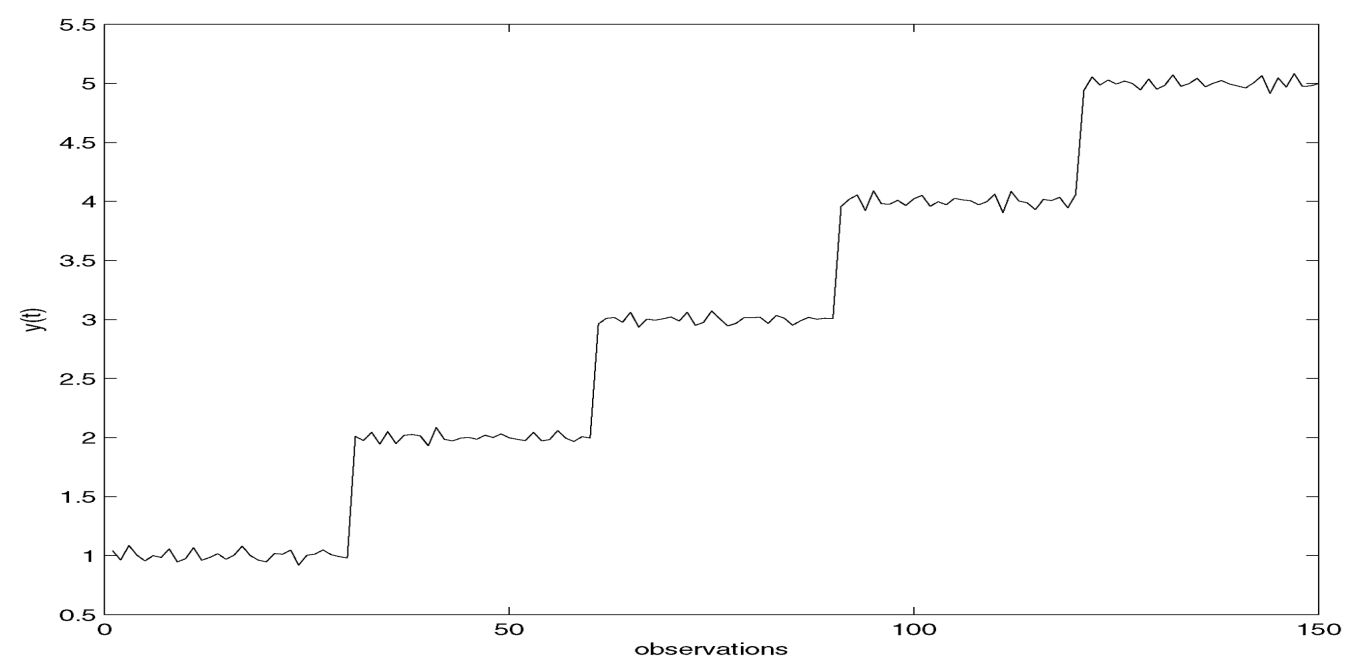

Figure 1 - Time series with $p_{1}=1, p_{2}=2, p_{3}=3, p_{4}=4, p_{5}=5, m_{1}=30, m_{2}=60, m_{3}=90$, $m_{4}=120$ and $\varepsilon(t) \sim U(0,1)$ for 150 observations.

The proposed fuzzy clustering to transform a given time series into a new one is described below:

1. Input the time series $y(t)$;

2. Find the set of $k$ centers, $C=\left\{C_{i} \mid \min \{y(t)\} \leq C_{i} \leq \max \{y(t)\}, i=1,2, \ldots, k\right\}$, that minimizes the Euclidean distance as (1), considering, for example, the time series (3) (Fig. 1).

3. Compute the fuzzy membership degree given in (2), for each sample of the time series, $y(t)$, with respect to each center $C_{i}$ (Fig. 3). 


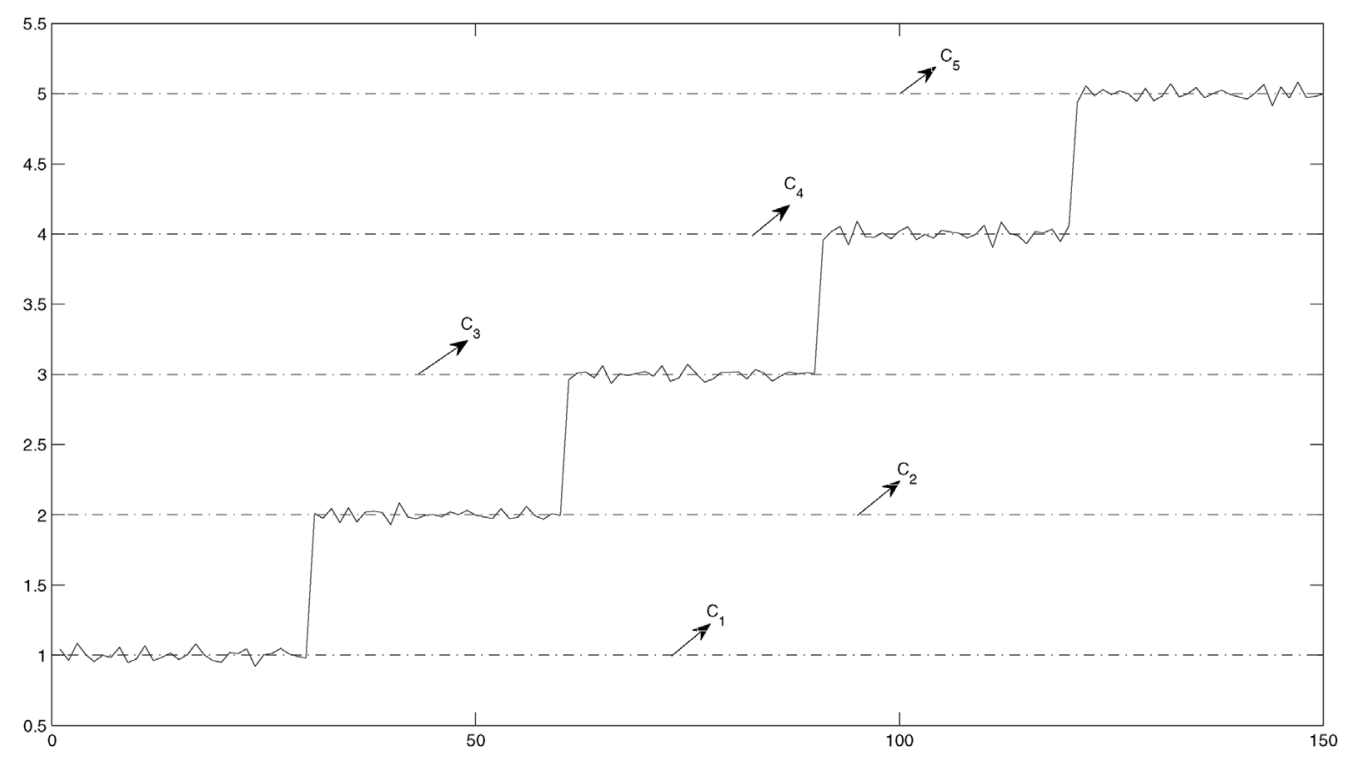

Figure 2 - Centers of time series of Figure 1.
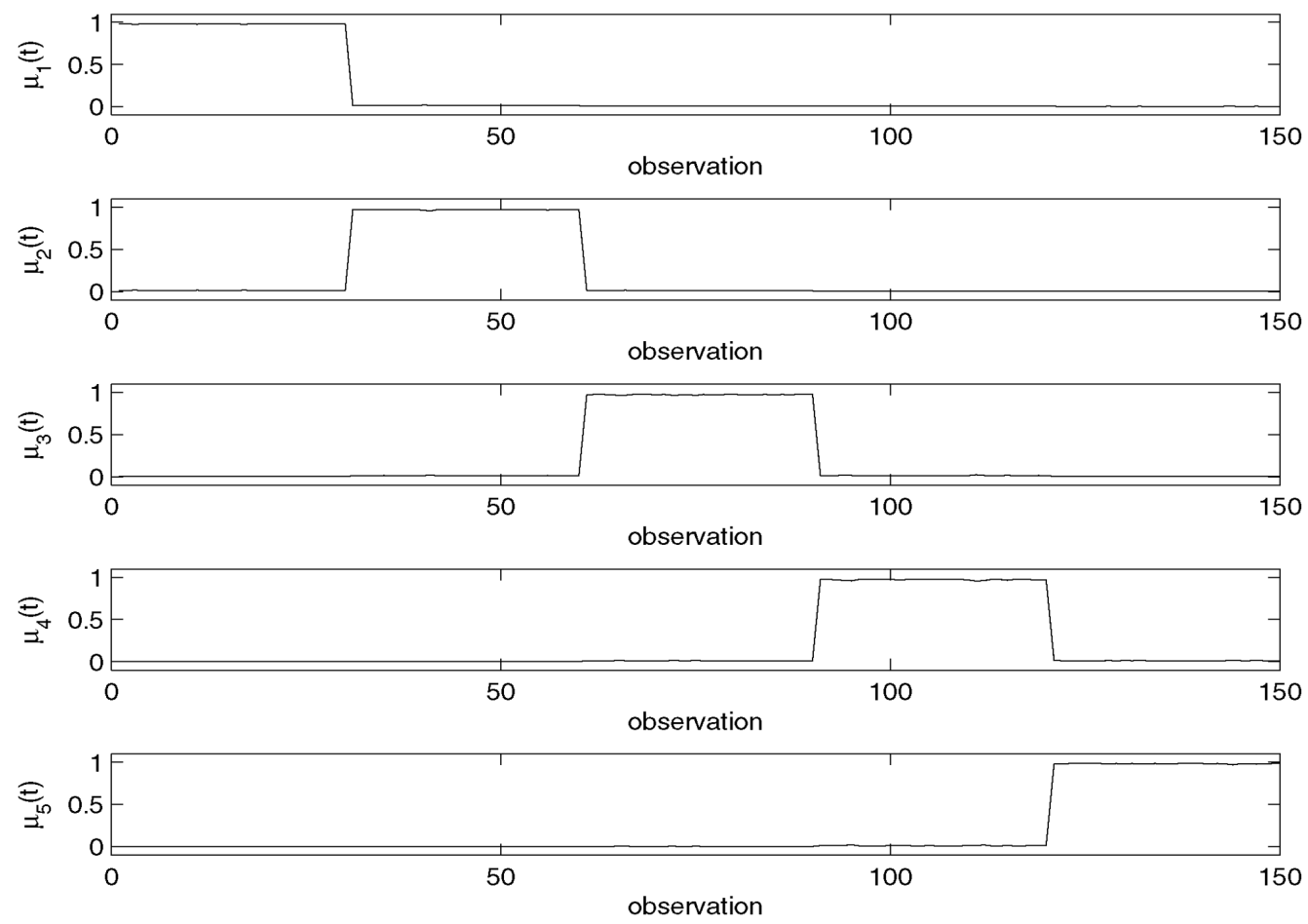

Figure 3 - Membership functions for each center of time series $y(t)$. 


\subsection{Formulation of the Metropolis-Hastings algorithm}

The goal of the Metropolis-Hastings algorithm [27] is to construct a Markov chain that has a certain equilibrium distribution $\pi$. Define a Markov chain as follows. If $X_{i-1}=x_{i-1}$, then generate a candidate value $X^{*}$ from a distribution with density $f_{X^{*} \mid X}(y)=1\left(x_{i-1}, x^{*}\right)$. The function $q$ (.) is known as the core transition of the Markov chain. The candidate value $X^{*}$ is accepted or rejected with a probability of acceptance:

$$
\alpha(x, y)=\min \left(1, \frac{\pi\left(x^{*}\right)}{\pi\left(x_{i-1}\right)} \frac{q\left(x^{*}, x_{i-1}\right)}{q\left(x_{i-1}, x^{*}\right)}\right)
$$

If the candidate is accepted, do $x_{i}=Y$, otherwise do $x_{i}=X_{i-1}$. Thus, if the candidate is rejected, the Markov chain repeats the sequence. It is possible to show that, under general conditions, the sequence $X_{0}, X_{1}, X_{2}, \ldots$ is a Markov chain with equilibrium distribution $\pi$. In practical terms, the Metropolis- Hastings algorithm can be specified by the following steps:

1. Choose an initial value $x_{0}$, the number of simulations, $R$, and make the simulations counter $r=1$;

2. Generate a candidate value $y \sim q\left(x_{i},.\right)$;

3. Calculate the probability of acceptance as in (4) and generate $u \sim U(0,1)$;

4. Calculate the new value of the current state:

$$
x^{t+1}=\left\{\begin{array}{ll}
y, & \text { if } \alpha(x, y)>u \\
x^{t}, & \text { otherwise }
\end{array}\right\}
$$

5. If $r<R$, return to step 2. Otherwise, stop.

Note that, as discussed in [21], the quantization technique generates a time series transformed to the first and last membership degree with the following probability distribution:

$$
\begin{array}{ll}
\mu_{i}(t) \sim \operatorname{Beta}(a, b), & \text { for } t=1, \ldots, m \\
\mu_{i}(t) \sim \operatorname{Beta}(c, d), & \text { for } t=m+1, \ldots, n
\end{array}
$$

The parameters to be estimated by Metropolis-Hastings algorithm are $a, b, c, d$ and the change point $m$. In this type of algorithm, usually, uninformative priors are used, for example:

$$
\begin{aligned}
a & \sim \operatorname{Gamma}(0.1,0.1) \\
b & \sim \operatorname{Gamma}(0.1,0.1) \\
c & \sim \operatorname{Gamma}(0.1,0.1) \\
d & \sim \operatorname{Gamma}(0.1,0.1) \\
m & \sim U[1, \ldots, n], \text { with } p(m)=\frac{1}{n}
\end{aligned}
$$


The Gamma distribution with parameters shape and scale equal to 0.1 was chosen because it is uninformative, with the goal of sweeping the entire parameter space. Considering the intermediate membership degree, we have the following probability distribution:

$$
\begin{array}{ll}
\mu_{i}(t) \sim \operatorname{Beta}(a, b), & \text { for } t=1, \ldots, m_{i-1} \\
\mu_{i}(t) \sim \operatorname{Beta}(c, d), & \text { for } t=m_{i-1}+1, \ldots, m_{i} \\
\mu_{i}(t) \sim \operatorname{Beta}(e, f), & \text { to } m_{i}=t+1, \ldots, n
\end{array}
$$

The parameters to be estimated by Metropolis- Hastings algorithm are $a, b, c, d, e, f$ and the second point of change, $m_{i}$, whereas the first switch point, $m_{i-1}$ is identified in the previous step. In this type of algorithm uninformative priors are commonly used, for example:

$$
\begin{aligned}
a & \sim \operatorname{Gamma}(0.1,0.1) \\
b & \sim \operatorname{Gamma}(0.1,0.1) \\
c & \sim \operatorname{Gamma}(0.1,0.1) \\
d & \sim \operatorname{Gamma}(0.1,0.1) \\
e & \sim \operatorname{gamma}(0.1,0.1) \\
f & \sim \operatorname{Gamma}(0.1,0.1) \\
m_{i} & \sim U\left[m_{i-1}, \ldots, n\right], \text { with } p(m)=\frac{1}{n-m_{i}}
\end{aligned}
$$

The transition kernels of the Markov chain for the model with a single point of change and for the model with two change points are presented in appendices A and B, respectively.

\subsection{Example of multiple change point detection in time series presented in Figure 1}

The proposed fuzzy/Bayesian multiple change points detection in time series is described below:

1. Input the time series $y(t)$ (Fig. 1);

2. Find the set of $k$ centers, $C=\left\{C_{i} \mid \min \{y(t)\} \leq C_{i} \leq \max \{y(t)\}, i=1,2, \ldots, k\right\}$, given by Figure 2.

3. Compute the fuzzy membership degree given in (2), for each sample of the time series, $y(t)$, with respect to each center $C_{i}$, illustrated by Figure 3 .

4. Compute Metropolis-Hastings Algorithm in each membership function for change point detection as illustrated in Figure 4 (for first and last membership function is executed the detection of the one change point, and in the others membership functions is executed the detection of the two change points). The final analysis is performed as: the change point, $m_{i}$, is obtained by checking where the maximum of $m_{i}$ histogram occurs.

\section{CASE STUDY: MONITORING INDUCTION MACHINE WITH TURN-TO-TURN SHORT CIRCUIT IN STATOR WINDING}

Many studies have shown that a large proportion of induction machine faults are related to the stator-winding [10], [24], [53], [61]. The induction machine stator-winding is subject to stress 

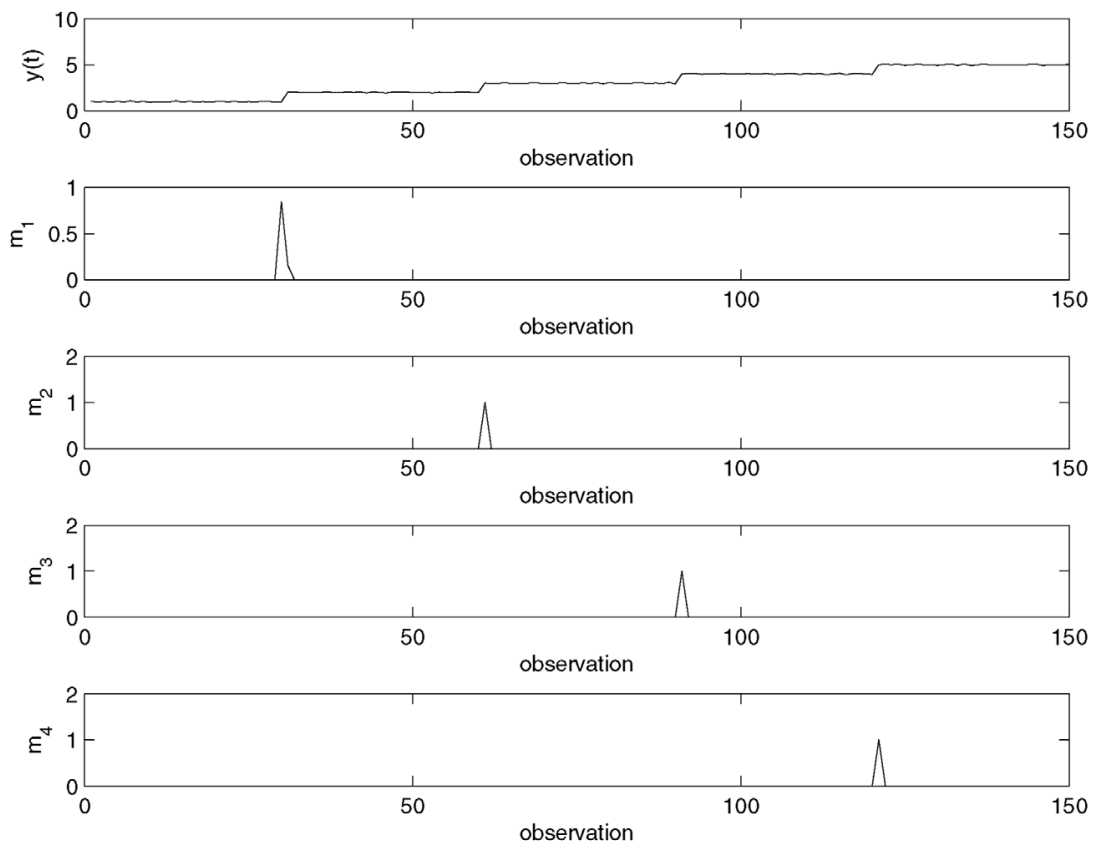

Figure 4 - Results of proposed methodology.

due to many factors, which include thermal overload, mechanical vibration and peak voltage caused by a speed controller. The deterioration of insulation usually begins as a short circuit fault of the stator-winding. This section describes the model that is employed here for the simulation of inter-turn short circuits in the stator windings of induction machines.

This work employs a generic model for the machine [8], valid for any $d q$ (direct and quadrature) axis speed obtained by the Park's transformation [37]. Representing the currents, voltages and electromagnetic flows by $i, v$ and $\lambda$, the resistance, leakage and mutual inductance by $r, L_{l}$ and $L_{m}$, the phases $a, b$ and $c$ by indexes $a, b$ and $c$, the windings of the stator and rotor by indexes $s$ and $r$, the stator and rotor voltages equations become:

$$
\begin{aligned}
& {\left[v_{s}\right]=\left[r_{s}\right]\left[i_{s}\right]+\frac{d\left[\lambda_{s}\right]}{d t}} \\
& {\left[v_{r}\right]=\left[r_{r}\right]\left[i_{r}\right]+\frac{d\left[\lambda_{r}\right]}{d t}}
\end{aligned}
$$

where

$$
\begin{aligned}
{\left[v_{s}\right.} & =\left[\begin{array}{llll}
v_{a s 1} & v_{a s 2} & v_{b s} & v_{c s}
\end{array}\right]^{T} \\
{\left[v_{r}\right] } & =\left[\begin{array}{llll}
v_{a r} & v_{b r} & v_{c r}
\end{array}\right]^{T} \\
{\left[i_{s}\right.} & =\left[\begin{array}{llll}
i_{a s} & i_{a s}-i_{f} & i_{b s} & i_{c s}
\end{array}\right]^{T} \\
{\left[i_{r}\right] } & =\left[\begin{array}{llll}
i_{a r} & i_{b r} & i_{c r}
\end{array}\right]^{T}
\end{aligned}
$$




$$
\begin{aligned}
& {\left[\lambda_{s}\right]=\left[\begin{array}{llll}
\lambda_{a s 1} & \lambda_{a s 2} & \lambda_{b s} & \lambda_{c s}
\end{array}\right]^{T}} \\
& {\left[\begin{array}{ll}
\lambda_{r}
\end{array}\right]=\left[\begin{array}{lll}
\lambda_{a r} & \lambda_{b r} & \lambda_{c r}
\end{array}\right]^{T}}
\end{aligned}
$$

In the above, the index $a s_{2}$ represents the shorted turns and $i_{f}$ is the current in the shorted turns. Figure 5 represents the schematic diagram of a motor with an inter-turn short circuit.

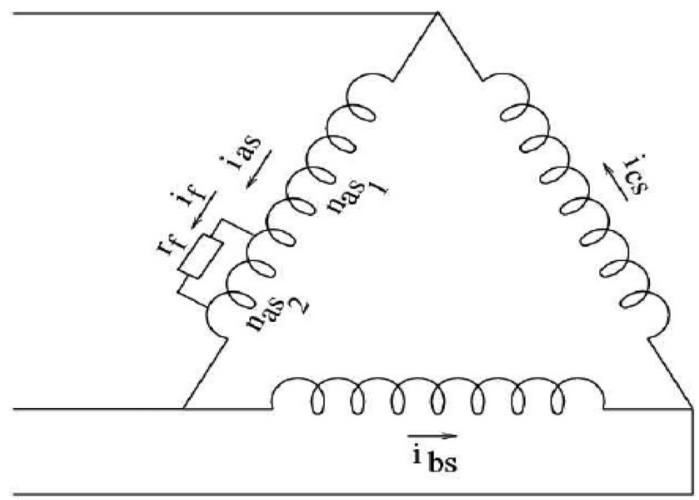

Figure 5 - Representation of stator windings of a motor with inter-turn short circuit.

In the model proposed in reference [8], the stator windings voltages are given by:

$$
\begin{gathered}
V_{d s}+\frac{2}{3} \mu r_{s} i_{f} \cos \theta=r_{s} i_{d s}+\frac{d \lambda_{d s}}{d t}+\omega \lambda_{q s} \\
V_{q s}+\frac{2}{3} \mu r_{s} i_{f} \sin \theta=r_{s} i_{q s}+\frac{d \lambda_{q s}}{d t}+\omega \lambda_{d s} \\
V_{0 s}+\frac{1}{3} \mu r_{s} i_{f}=r_{s} i_{0 s}+\frac{d \lambda_{0 s}}{d t}
\end{gathered}
$$

The rotor circuit equations are the same as for traditional symmetrical model.

The stator and the rotor electromagnetic flows of stator in $d q$ axis, are given by:

$$
\begin{gathered}
\lambda_{d s}=L_{s} i_{d s}+L_{m} i_{d r}-\frac{2}{3} \mu L_{s} i_{f} \cos \theta \\
\lambda_{q s}=L_{s} i_{q s}+L_{m} i_{q r}-\frac{2}{3} \mu L_{s} i_{f} \sin \theta \\
\lambda_{0 s}=L_{l s} i_{0 s}+\frac{\mu}{3} L_{l s} i_{f} \sin \theta \\
\lambda_{d r}=L_{r} i_{d r}+L_{m} i_{d s}-\frac{2}{3} \mu L_{m} i_{f} \cos \theta \\
\lambda_{q r}=L_{r} i_{q r}+L_{m} i_{q s}-\frac{2}{3} \mu L_{m} i_{f} \sin \theta
\end{gathered}
$$


The voltage and the induced electromagnetic flow in the short-circuit turns are given by:

$$
\begin{gathered}
v_{a s 2}=\mu r_{s}\left(i_{d s} \cos \theta+i_{q s} \sin \theta-i_{f}\right)+\frac{d \lambda_{a s 2}}{d t} \\
\lambda_{a s 2}=\mu L_{l s}\left(i_{q s} \sin \theta+i_{d s} \cos \theta-i_{f}\right) \\
+\mu L_{m}\left(i_{q s} \sin \theta+i_{d s} \cos \theta+i_{q r} \sin \theta+i_{d r} \cos \theta-\frac{2}{3} \mu i_{f}\right)
\end{gathered}
$$

The electromagnetic torque is given by:

$$
T=\frac{3}{2} \frac{p}{2} L_{m}\left(i_{q s} i d r-i_{d s} i q r\right)-\frac{p}{2} \mu L_{m} i_{f} i_{q r}
$$

The induction machine stator current simulation results for a fault beginning which $2 \%$ of turns in the phase $a$ become in short circuit after the time $2 s$ and increase of $2 \%$ every time of $2 s$ to reach a level of $8 \%$ of short-circuit is shown in the Figure 6 . The root mean square (rms) current values is illustrated in Figure 7. The proposed monitoring for future fault detection approach here is based on finding such events of non-balanced changes in the current $r m s$ values.

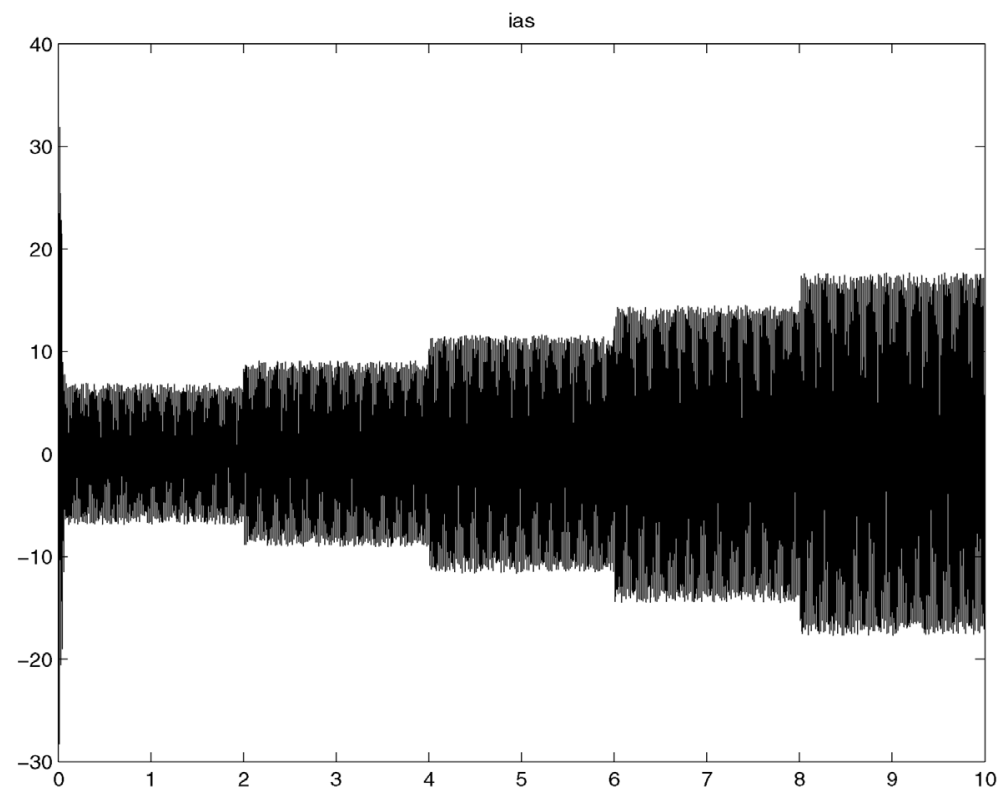

Figure 6 - Current of phase $a$.

\subsection{Results of Proposed Methodology}

The simulation results of current monitoring in the stator winding of an induction machine with star connection are shown in Figure 8, considering become in short circuit after the time $2 s$ and increase of $2 \%$ every time of $2 s$ to reach a level of $8 \%$ of short-circuit, was shown in the Figure 6 . These results have been obtained by simulation of the induction machine using the model 


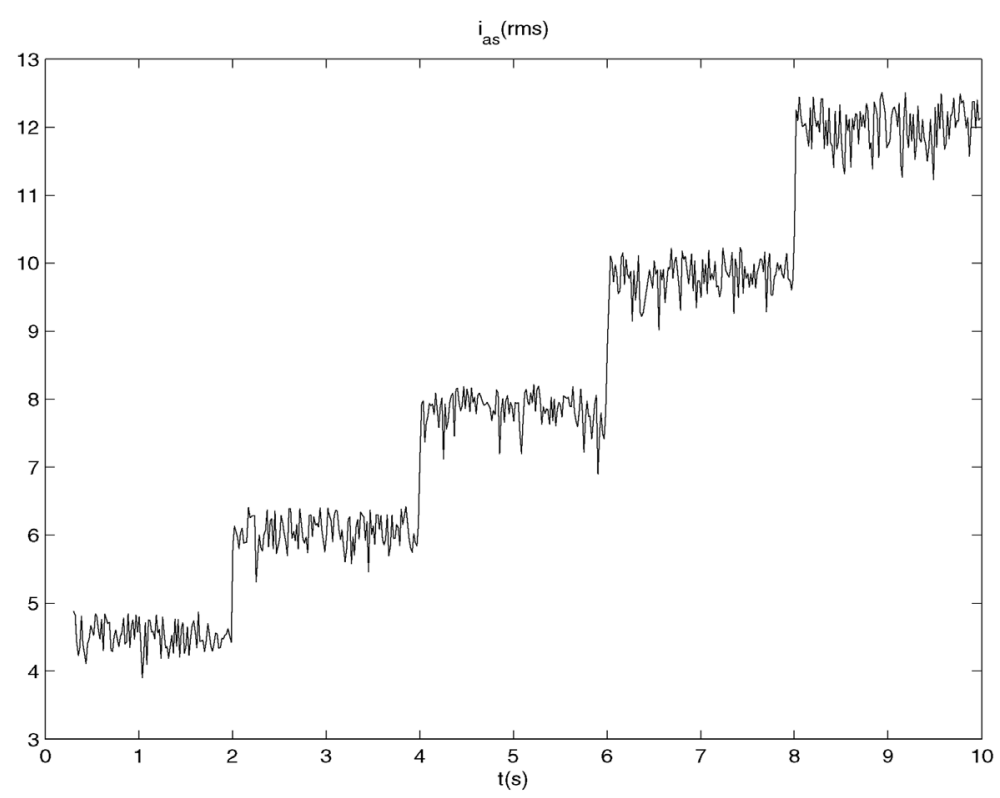

Figure 7 - rms current of phase $a$.

described in this Section and the change point detection methodology presented in Section 2. The centers in the induction machine currents are found by optimization of the Average Silhouette Width [55].

\section{CONCLUSIONS}

In this paper a novel fuzzy/Bayesian methodology for multiple change points detection in time series has been used to treat the on-line current monitoring of the induction machine statorwinding. The methodology is based on a two-step formulation: Firstly, a fuzzy clustering generates a transformed time series with beta distribution. In the second step, a Metropolis-Hastings algorithm is used to detect the probability of the occurrence of one change point or two change points in the transformed time series. This two-step formulation allows a systematic efficient way to solve a change point detection problem, which is employed for detecting incipient faults as change points that occur in some system signal. The proposed methodology has as advantages, compared to other techniques for the FDI problem, the fact that no mathematical models of the motor and no previous knowledge of signal statistical distributions are necessary, and also an enhanced resilience against false alarms, combined with a good sensitivity that allows the detection of rather small fault signals. This methodology has been successfully applied: Simulation results have been presented as evidences of the effectiveness of the proposed methodology, even in the case of faults that cause very low level disturbances. In the future, new methods of data clustering and other uninformative priors can be used to increase the efficiency of the proposed methodology. 

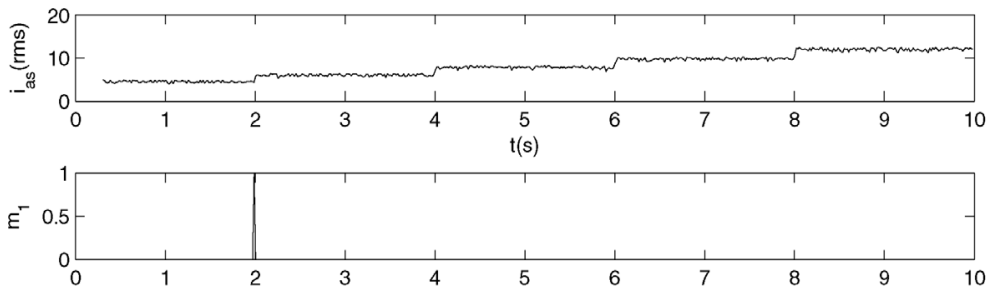

$t(s)$

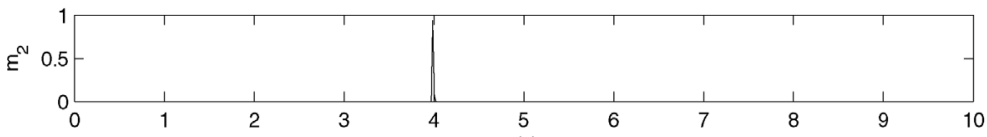

$\mathrm{t}(\mathrm{s})$

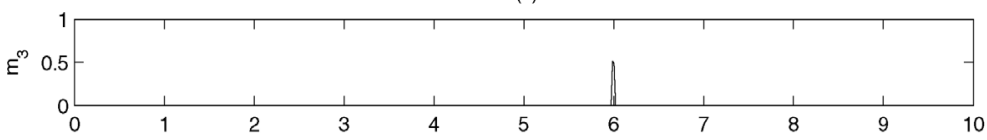

t(s)

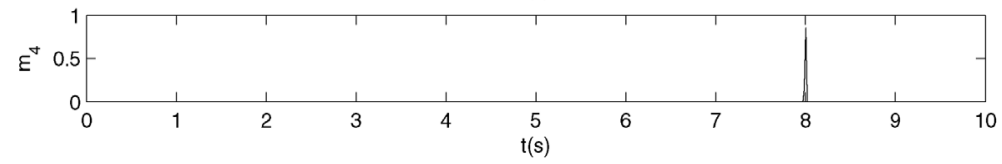

Figure 8 - rms current of phase $a$ and the results of proposed methodology.

\section{ACKNOWLEDGEMENTS}

This work has been supported in part by the Brazilian agencies CNPq and FAPEMIG.

\section{REFERENCES}

[1] Alavi SMM, Izadi-Zamanabadi R \& Hayes MJ. 2008. Robust fault detection and isolation technique for single-input/single-output closed-loop control systems that exhibit actuator and sensor faults. IET Control Theoty and Applications, 2(11): 951-965.

[2] Arkan M, Perovic DK \& Unsworth P. 2001. Online stator fault diagnosis in induction motors. IEE Proceedings Electronic Power Application, 148(6): 537-547, November.

[3] BEZDEK JC. 1981. Pattern recognition with fuzzy objective function algorithms. Plenum Press.

[4] BARRY D \& HARTIGAN JA. 1993. A Bayesian analysis for change point problems. Journal of the American Statistical Association, 88(421): 309-319.

[5] Boukhobza T, Hamelin F \& Canitrot S. 2008. A graph-theoretic approach to fault detection and isolation for structured bilinear systems. International Journal of Control, 81(4): 661-678.

[6] Boqiang X, Heming L \& Sun LiLing. 2003. Apparent impedance angle based detection of stator winding interturn short circuit fault in induction motors. In Proceedings of the Industry Application Conference, pages 1118-1125.

[7] Beckage B, Joseph L, Belisle P, Wolfson DB \& Platt WJ. 2007. Bayesian change-point analyses in ecology. New Phytologist, 174(2): 456-467. 
[8] Baccarini LMR, Menezes BR \& Caminhas WM. 2010. Fault induction dynamic model, suitable for computer simulation: simulation results and experimental validation. Mechanical Systems and Signal Processing, 24: 300-311.

[9] Baccarini LMR, Menezes BR, Guimarẽes HN \& Caminhas WM. 2006. A method for early detection of stator winding faults. In Proceedings of VII International Conference on Industrial Applications, pages 1-6, Recife/Brazil.

[10] Ballal MS, Suryawanshi HM \& Mishra MK. 2008. Detection of incipient faults in induction motors using FIS, ANN and ANFIS techniques. Journal of Power Electronics, 8(2): 181-191.

[11] CRuz SMA \& CARdoso JM. 2004. Diagnosis of stator interturn short circuits in dtc induction motor drives. IEEE Transactions on Industry Applications, 40(5): 1349-1360.

[12] Calado JMF, Korbicz J, Patan K, Patton RJ \& da Costa JMgS. 2001. Soft computing approaches to fault diagnosis for dynamic systems. European Journal of Control, 7(2-3): 248-286.

[13] Cheng H, Nikus M \& Jamsa-Jounela S. 2008. Fault diagnosis of the paper machine short circulation process using novel dynamic causal digraph reasoning. Journal of Process Control, 18(78): 676-691.

[14] Chen J \& Patton RJ. 1999. Robust model-based fault diagnosis for dynamic systems. Dordrecht: Kluwer Academic Publishers.

[15] CHEN W \& SAIF M. 2007. Observer-based strategies for actuator fault detection, isolation and estimation for certain class of uncertain nonlinear systems. IET Control Theoty and Applications, 1(6): $1672-1680$.

[16] Caminhas WM \& Takahashi RHC. 2001. Dynamic system failure detection and diagnosis employing sliding mode observers and fuzzy neural networks. In Proceedings of the Joint 9th IFSA and 20th NAFIPS, pages 304-309, Vancouver.

[17] D'Angelo MFSV \& Costa PP. 2001. Detection of shorted turns in the field winding of turbogenerators using the neural network mlp. In Proceedings of the IEEE International Conference on Systems, Man, and Cybernetics, pages 1930-1935, Tucson.

[18] Detroja KP, Gudi RD \& Patwardhan SC. 2006. A possibilistic clustering approach to novel fault detection and isolation. Journal of Process Control, 16(10): 1055-1073.

[19] D’ Angelo MFS V, Palhares RM, Cosme LB, Aguiar La, Fonseca FS \& Caminhas WM. 2014. Fault detection in dynamic systems by a fuzzy/bayesian network formulation. Applied Soft Computing, 21: 647-653.

[20] D’ Angelo MFSV, Palhares RM, Takahashi RHC, Loschi RH, Baccarini LMR \& CAMINHAS WM. 2011. Incipient fault detection in induction machine stator-winding using a fuzzyBayesian change point detection approach. Applied Soft Computing, 11(1): 179-192.

[21] D’Angelo MFSV, Palhares RM, Takahashi RHC \& Loschi RH. 2011. A fuzzy/bayesian approach for the time series change point detection problem. Pesquisa Operacional, 31: 217-234.

[22] D’Angelo MFSV, Palhares RM, Takahashi RHC \& Loschi RH. 2011. Fuzzy/Bayesian change point detection approach to incipient fault detection. IET Control Theory \& Applications, 5(4): 539-551.

[23] Dutuit Y \& RAUZY A. 2005. Approximate estimation of system reliability via fault trees. Reliability Engineering \& System Safety, 87(2): 163-172. 
[24] Da Silva AM, Povinelli RJ \& Demerdash NAO. 2008. Induction machine broken bar and stator short-circuit fault diagnostics based on three-phase stator current envelopes. IEEE Transactions on Industrial Electronics, 55(3): 1310-1318.

[25] El-Shal SM \& Morris AS. 2000. A fuzzy expert system for fault detection in statistical process control of industrial processes. IEEE Transactions on Systems, Man and Cybernetics, Part C, 30(2): 281-289.

[26] FONG KF, LOH AP \& TAN WW. 2008. A frequency domain approach for fault detection. International Journal of Control, 81(2): 264-276.

[27] Gamerman D. 1997. Markov chain Monte Carlo: stochastic simulation for Bayesian inference. Chapman \& Hall.

[28] GAO H, CHEN T \& WANG L. 2008. Robust fault detection with missing measurements. International Journal of Control, 81(5): 804-819.

[29] GaO Z, WANG H \& CHAI T. 2007. A robust fault detection filtering for stochastic distribution systems via descriptor estimator and parametric gain design. IET Control Theoty and Applications, 1(5): 1286-1293.

[30] Hartigan JA. 1990. Partition models. Communication in Statistics-Theory and Methods, 19(8): $2745-2756$.

[31] HINKEY DV. 1971. Inference about the change point from cumulative sum test. Biometria, 26: 279284.

[32] Hadjiliadis O \& Moustakides V. 2006. Optimal and asymptotically optimal cusum rules for change point detection in the brownian motion model with multiple alternatives. Theory of Probability and its Applications, 50(1): 75-85.

[33] ISERMANn R \& BALLE P. 1997. Trends in the application of model-based fault detection and diagnosis of technical processes. Control Engineering Practice, 5(5): 707-719.

[34] Iravani MR \& Karimi-Ghartemani M. 2003. Online estimation of steady state and instantaneous symmetrical components. IEE Proceedings Generation, Transmission and Distribution, 150(5): 616-622, September.

[35] Kohonen T. 2001. Self-organizing maps. Springer Series in Information Sciences. Springer.

[36] KaUfman L \& Rousseeuw PJ. 1990. Finding groups in data: An introduction to cluster analysis. John Wiley \& Sons.

[37] Krause PC. 1986. Analysis of Electric Machinery. McGraw-Hill.

[38] Laurentys CA, Bomfim CHM, Menezes BR \& Caminhas WM. 2011. Design of a pipeline leakage detection using expert system: A novel approach. Applied Soft Computing, 11(1): 10571066.

[39] LosChi RH \& CRUZ FRB. 2005. Bayesian identification of multiple change points in poisson data. Advances in Complex Systems, 8: 465-482.

[40] Loschi RH \& CRUZ FRB. 2005. Extension to the product partition model: computing the probability of a change. Computational Statistics and Data Analysis, 48(2): 255-268. 
[41] Loschi RH, Gonçalves FB \& CRUz FRB. 2005. Avaliação de uma medida de evidência de um ponto de mudança e sua utilização na identificação de mudanças na taxa de criminalidade em belo horizonte. Pesquisa Operacional, 25(3): 459-463.

[42] Lee S, Nishiyama Y \& Yoshida N. 2006. Test for parameter change in diffusion processes by cusum statistics based on one-step estimators. Annals of the Institute of Statistical Mathematics, 58(2): 211-222.

[43] Laurentys CA, Palhares RM \& Caminhas WM. 2010. Design of an artificial immune system based on danger model for fault detection. Expert Systems with Applications, 37(7): 5145-5152.

[44] Laurentys CA, Palhares RM \& Caminhas WM. 2011. A novel artificial immune system for fault behavior detection. Expert Systems with Applications, 38(11): 6957-6966.

[45] Lee S, Park S, Maekawa K \& Kawai K. 2006. Test for parameter change in arima models. Communications in Statistics: Simulation and Computation, 35(2): 429-439.

[46] Moreira FS, D’Angelo MFsV, Palhares RM \& Caminhas WM. 2010. Incipient fault detection in induction machine stator-winding using a fuzzy-Bayesian two change points detection approach. In 9th IEEE/IAS International Conference on Industry Applications.

[47] Maurya Mr, Rengaswamy R \& Venkatasubramanian V. 2006. A signed directed graphbased systematic framework for steady-state malfunction diagnosis inside control loops. Chemical Engineering Science, 61(6): 1790-1810.

[48] Maurya Mr, Rengaswamy R \& Venkatasubramanian V. 2007. Fault diagnosis using dynamic trend analysis: A review and recent developments. Engineering Applications of Artificial Intelligence, 20(2): 133-146.

[49] OH KJ, RoH TH \& Moon MS. 2005. Developing time-based clustering neural networks to use change-point detection: Application to financial time series. Asia-Pacific Journal of Operational Research, 22(1): 51-70.

[50] Ploix S \& Adrot O. 2006. Parity relations for linear uncertain dynamic systems. Automatica, 42(9): 1553-1562.

[51] PATAN K \& PARisini T. 2005. Identification of neural dynamic models for fault detection and isolation: the case of a real sugar evaporation process. Journal of Process Control, 15(1): 67-79.

[52] Puig V, Stancu A, Escobet T, Nejuari F, Quevedo J \& Patton RJ. 2006. Passive robust fault detection using interval observers: Application to the DAMADICS benchmark problem. Control Engineering Practice, 14(6): 621-633.

[53] Rodriguez PVJ \& ARKKIO A. 2008. Detection of stator winding fault in induction motor using fuzzy logic. Applied Soft Computing, 8: 1112-1120.

[54] Ragot J \& Maquin D. 2006. Fault measurement detection in an urban water supply network. Journal of Process Control, 16(9): 887-902.

[55] Rousseouw PJ. 1987. Silhouettes: a Graphical Aid to the interpretation and Validation of Cluster Analysis. Computacion and Applied Mathematics, 20: 53-65.

[56] Rajagopalan S, Restrepo Ja, Aller JM, Habetler TG \& Harley RG. 2008. Nonstationary motor fault detection using recent quadratic time-frequency representations. IEEE Transactions on Industry Applications, 44(3): 735-744. 
[57] Silva GC, Palhares RM \& Caminhas WM. 2012. Immune inspired fault detection and diagnosis: A fuzzy-based approach of the negative selection algorithm and participatory clustering. Expert Systems with Applications, 39(16): 12474-12486.

[58] Sottile J, Trutt FC \& Kohler JL. 2000. Experimental investigation of on-line methods for incipient fault detection in induction motors. In Proceedings of the Industry Application Conference, pages 2682-2687.

[59] Thomson WT \& Fenger M. 2001. Current signature analysis to detect induction motor faults. IEEE Industry Applications Magazine, 7: 26-34, July/August.

[60] Tallam RM, Lee SB, Stone G, Kliman GB, Yoo J, Habetler TJ \& Harley RG. 2003. A survey of methods for detection of stator faults in induction machines. In Proceedings of SDEMPED, Diagnostics for Electric Machines, Power Eletronics and Drives, pages 35-46.

[61] Tallam RM, Lee Sb, Stone GC, Kliman GB, Yoo J, Habetler TG \& Harley RG. 2007. A survey of methods for detection of stator-related faults in induction machines. IEEE Transactions on Industry Applications, 43(4): 920-933.

[62] TAKahashi RHC \& PeRes PLD. 1999. Unknown input observers for uncertain systems: A unifying approach. European Journal of Control, 5(2-4): 261-275.

[63] Takahashi RhC, Palhares RM \& Peres PlD. 1999. Discrete-time singular observers: $\mathcal{H}_{2} / \mathcal{H}_{\infty}$ optimality and unknown inputs. International Journal of Control, 72(6): 481-492.

[64] Uppal FJ, PATton RJ \& WitcZak M. 2006. A neuro-fuzzy multiple-model observer approach to robust fault diagnosis based on the DAMADICS benchmark problem. Control Engineering Practice, 14(6): 699-717.

[65] Verron S, Li J \& Tiplica T. 2010. Fault detection and isolation of faults in a multivariate process with Bayesian network. Journal of Process Control, 20(8): 902-911.

[66] Venkatasubramanian V, Rengaswamy R \& KaVuri SN. 2003. A review of process fault detection and diagnosis - part II: Qualitative models and search strategies. Computers and Chemical Engineering, 27: 313-326.

[67] Venkatasubramanian V, Rengaswamy R, KaVuri SN \& Yin K. 2003. A review of process fault detection and diagnosis - part III: Process history based methods. Computers and Chemical Engineering, 27: 327-346.

[68] Venkatasubramanian V, Rengaswamy R, Yin K \& Kavuri SN. 2003. A review of process fault detection and diagnosis - part I: Quantitative model-based methods. Computers and Chemical Engineering, 27: 293-311.

[69] Verron S, Tiplica T \& Kobi A. 2008. Fault detection and identification with a new feature selection based on mutual information. Journal of Process Control, 18(5): 479-490.

[70] XU BG. 2012. Intelligent fault inference for rotating flexible rotors using Bayesian belief network. Expert Systems with Applications, 39(1): 816-822.

[71] ZADEH LA. 1965. Fuzzy sets. Information and Control, 8(3): 338-353.

[72] ZolghadRi A. 1996. An algorithm for real-time failure detection in Kalman filters. IEEE Transactions on Automatic Control, 41(10): 1537-1539. 


\section{APPENDIX A}

This appendix is intended to build the probabilities of acceptance for the posterior distribution of the parameters $a, b, c, d$ and $m$ described in the Metropolis-Hastings algorithm. The reference distributions used in the work are the prior distributions, i.e., the $\operatorname{Gamma}(0.1,0.1)$, that have been chosen to be uninformative.

1. For the parameter $a$ :

$$
\begin{gathered}
\frac{\Pi\left(a^{*}\right)}{\Pi\left(a_{i-1}\right)} \frac{q\left(a^{*}, a_{i-1}\right)}{q\left(a_{i-1}, a^{*}\right)}= \\
\frac{\left[\frac{\Gamma\left(a^{*}+b^{i-1}\right)}{\Gamma\left(a^{*}\right)}\right]^{m^{i-1}} \prod_{j=1}^{m^{i-1}} y_{j}^{a^{*}-1}\left\{\left[\frac{a^{i-1}}{a^{*}}\right]^{0.9} e^{-0.1\left(a^{*}-a^{i-1}\right)}\right\}^{2}}{\left[\frac{\Gamma\left(a^{i-1}+b^{i-1}\right)}{\Gamma\left(a^{i-1}\right)}\right]^{m^{i-1}} \prod_{j=1}^{m^{i-1}} y_{j}^{a^{i-1}-1}}
\end{gathered}
$$

2. For the parameter $b$ :

$$
\begin{gathered}
\frac{\Pi\left(b^{*}\right)}{\Pi\left(b_{i-1}\right)} \frac{q\left(b^{*}, b_{i-1}\right)}{q\left(b_{i-1}, b^{*}\right)}= \\
\frac{\left[\frac{\Gamma\left(a^{i}+b^{*}\right)}{\Gamma\left(b^{*}\right)}\right]^{m^{i-1}} \prod_{j=1}^{m^{i-1}}\left(1-y_{j}\right)^{b^{*}-1}\left\{\left[\frac{b^{i-1}}{b^{*}}\right]^{0.9} e^{-0.1\left(b^{*}-b^{i-1}\right)}\right\}^{2}}{\left[\frac{\Gamma\left(a^{i-1}+b^{i-1}\right)}{\Gamma\left(b^{i-1}\right)}\right]^{m^{i-1}} \prod_{j=1}^{m^{i-1}}\left(1-y_{j}\right)^{b^{i-1}-1}}
\end{gathered}
$$

3. For the parameter $c$ :

$$
\begin{gathered}
\frac{\Pi\left(c^{*}\right)}{\Pi\left(c_{i-1}\right)} \frac{q\left(c^{*}, c_{i-1}\right)}{q\left(c_{i-1}, c^{*}\right)}= \\
\frac{\left[\frac{\Gamma\left(c^{*}+d^{i-1}\right)}{\Gamma\left(c^{*}\right)}\right]^{n-m^{i-1}} \prod_{j=m^{i-1}+1}^{n} y_{j}^{c^{*}-1}\left\{\left[\frac{c^{i-1}}{c^{*}}\right]^{0.9} e^{-0.1\left(c^{*}-c^{i-1}\right)}\right\}^{2}}{\left[\frac{\Gamma\left(c^{i-1}+d^{i-1}\right)}{\Gamma\left(c^{i-1}\right)}\right]^{n-m^{i-1}} \prod_{j=m^{i-1}+1}^{n} y_{j}^{c^{i-1}-1}}
\end{gathered}
$$

4. For the parameter $d$ :

$$
\begin{gathered}
\frac{\Pi\left(d^{*}\right)}{\Pi\left(d_{i-1}\right)} \frac{q\left(d^{*}, d_{i-1}\right)}{q\left(d_{i-1}, d^{*}\right)}= \\
\frac{\left[\frac{\Gamma\left(c^{i}+d^{*}\right)}{\Gamma\left(d^{*}\right)}\right]_{j=m^{i-1}+1}^{n-m^{i-1}}\left(1-y_{j}\right)^{d^{*}-1}\left\{\left[\frac{d^{i-1}}{d^{*}}\right]^{0.9} e^{-0.1\left(d^{*}-d^{i-1}\right)}\right\}^{2}}{\left[\frac{\Gamma\left(c^{i-1}+d^{i-1}\right)}{\Gamma\left(d^{i-1}\right)}\right]^{n-m^{i-1}} \prod_{j=m^{i-1}+1}^{n}\left(1-y_{j}\right)^{d^{i-1}-1}}
\end{gathered}
$$


5. For the parameter $m$ :

$$
\begin{gathered}
\frac{\Pi\left(m^{*}\right)}{\Pi\left(m_{i-1}\right)} \frac{q\left(m^{*}, m\right)}{q\left(m_{i-1}, m^{*}\right)}= \\
\frac{\left[\frac{\Gamma\left(a^{i}+b^{i}\right)}{\Gamma\left(a^{i}\right) \Gamma\left(b^{i}\right)}\right]^{m^{*}}\left[\frac{\Gamma\left(c^{i}+d^{i}\right)}{\Gamma\left(c^{i}\right) \Gamma\left(d^{i}\right)}\right]^{n-m^{*}} \prod_{j=1}^{m^{*}}\left[y_{j}^{a^{i}-1}\left(1-y_{j}\right)^{b^{i}-1}\right] \prod_{j=m^{*}+1}^{n}\left[y_{j}^{c^{i}-1}\left(1-y_{j}\right)^{d^{i}-1}\right]}{\left[\frac{\Gamma\left(a^{i}+b^{i}\right)}{\Gamma\left(a^{i}\right) \Gamma\left(b^{i}\right)}\right]^{m^{i-1}}\left[\frac{\Gamma\left(c^{i}+d^{i}\right)}{\Gamma\left(c^{i}\right) \Gamma\left(d^{i}\right)}\right]^{n-m^{i-1}} \prod_{j=1}^{m^{i-1}}\left[y_{j}^{a^{i}-1}\left(1-y_{j}\right)^{b^{i}-1}\right] \prod_{j=m^{i-1}+1}^{n}\left[y_{j}^{c^{i}-1}\left(1-y_{j}\right)^{d^{i}-1}\right]}
\end{gathered}
$$

\section{APPENDIX B}

This appendix is intended to show the probabilities of acceptance for the posterior distributions of the parameters $a, b, c, d, e, f, m_{1}$ and $m_{2}$ described in the Metropolis-Hastings algorithm for the model with two changes and remembering that the point $m_{1}$ will always be obtained by the previous series, it is not necessary then that will be treasured. The reference distributions used here are his own prior distributions, which in this work distributions $\operatorname{Gamma}(0.1,0.1)$ were chosen to be uninformative.

1. For the parameter $a$ :

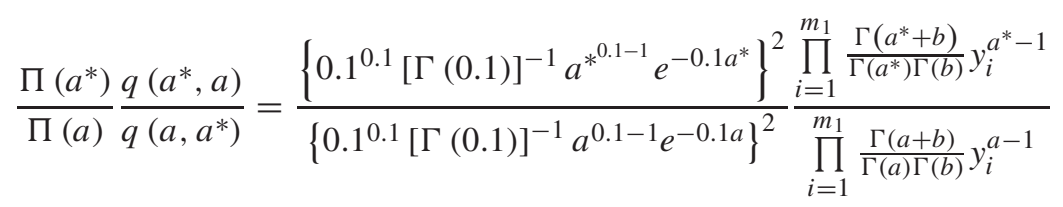

2. For the parameter $b$ :

$$
\frac{\Pi\left(b^{*}\right)}{\Pi(b)} \frac{q\left(b^{*}, b\right)}{q\left(b, b^{*}\right)}=\frac{\left\{0.1^{0.1}[\Gamma(0.1)]^{-1} b^{*^{0.1-1}} e^{-0.1 b^{*}}\right\}^{2}}{\left\{0.1^{0.1}[\Gamma(0.1)]^{-1} b^{0.1-1} e^{-0.1 b}\right\}^{2}} \frac{\prod_{i=1}^{m_{1}} \frac{\Gamma\left(a+b^{*}\right)}{\Gamma(a) \Gamma\left(b^{*}\right)} y_{i}^{b^{*}-1}}{\prod_{i=1}^{m_{1}} \frac{\Gamma(a+b)}{\Gamma(a) \Gamma(b)} y_{i}^{b-1}}
$$

3. For the parameter $c$ :

$$
\frac{\Pi\left(c^{*}\right)}{\Pi(c)} \frac{q\left(c^{*}, c\right)}{q\left(c, c^{*}\right)}=\frac{\left\{0.1^{0.1}[\Gamma(0.1)]^{-1} c^{*^{0.1-1}} e^{-0.1 c^{*}}\right\}^{2}}{\left\{0.1^{0.1}[\Gamma(0.1)]^{-1} c^{0.1-1} e^{-0.1 c}\right\}^{2}} \frac{\prod_{i=m_{1}+1}^{m_{2}} \frac{\Gamma\left(c^{*}+b\right)}{\Gamma\left(c^{*}\right) \Gamma(d)} y_{i}^{c^{*}-1}}{\prod_{i=m_{1}+1}^{m_{2}} \frac{\Gamma(c+d)}{\Gamma(c) \Gamma(d)} y_{i}^{c-1}}
$$

4. For the parameter $d$ :

$$
\frac{\Pi\left(d^{*}\right)}{\Pi(d)} \frac{q\left(d^{*}, d\right)}{q\left(d, d^{*}\right)}=\frac{\left\{0.1^{0.1}[\Gamma(0.1)]^{-1} d^{*^{0.1-1}} e^{-0.1 d^{*}}\right\}^{2}}{\left\{0.1^{0.1}[\Gamma(0.1)]^{-1} d^{0.1-1} e^{-0.1 d}\right\}^{2}} \frac{\prod_{i=m_{1}+1}^{m_{2}} \frac{\Gamma\left(c+d^{*}\right)}{\Gamma(c) \Gamma\left(d^{*}\right)} y_{i}^{d^{*}-1}}{\prod_{i=m_{1}+1}^{m_{2}} \frac{\Gamma(c+d)}{\Gamma(c) \Gamma(d)} y_{i}^{d-1}}
$$


5. For the parameter $e$ :

$$
\frac{\Pi\left(e^{*}\right)}{\Pi(e)} \frac{q\left(e^{*}, e\right)}{q\left(e, e^{*}\right)}=\frac{\left\{0.1^{0.1}[\Gamma(0.1)]^{-1} e^{*^{0.1-1}} e^{-0.1 e^{*}}\right\}^{2}}{\left\{0.1^{0.1}[\Gamma(0.1)]^{-1} e^{0.1-1} e^{-0.1 e}\right\}^{2}} \frac{\prod_{i=m_{2}+1}^{n} \frac{\Gamma\left(e^{*}+f\right)}{\Gamma\left(e^{*}\right) \Gamma(f)} y_{i}^{e^{*}-1}}{\prod_{i=m_{2}+1}^{n} \frac{\Gamma(e+f)}{\Gamma(e) \Gamma(f)} y_{i}^{e-1}}
$$

6. For the parameter $f$ :

$$
\frac{\Pi\left(f^{*}\right)}{\Pi(f)} \frac{q\left(f^{*}, f\right)}{q\left(f, f^{*}\right)}=\frac{\left\{0.1^{0.1}[\Gamma(0.1)]^{-1} f^{*^{0.1-1}} e^{-0.1 f^{*}}\right\}^{2}}{\left\{0.1^{0.1}[\Gamma(0.1)]^{-1} f^{0.1-1} e^{-0.1 f}\right\}^{2}} \frac{\prod_{i=m_{2}+1}^{n} \frac{\Gamma\left(e+f^{*}\right)}{\Gamma(e) \Gamma\left(f^{*}\right)} y_{i}^{f^{*}-1}}{\prod_{i=m_{2}+1}^{n} \frac{\Gamma(e+f)}{\Gamma(e) \Gamma(f)} y_{i}^{f-1}}
$$

7. For the parameter $m_{2}$ :

$$
\begin{gathered}
\frac{\Pi\left(m_{2}^{*}\right)}{\Pi\left(m_{2}\right)} \frac{q\left(m_{2}^{*}, m_{1}\right)}{q\left(m_{2}, m_{2}^{*}\right)}=\frac{\left[\frac{\Gamma(c+d)}{\Gamma(c) \Gamma(d)}\right]^{m_{2}^{*}-m_{1}}\left[\frac{\Gamma(e+f)}{\Gamma(e) \Gamma(f)}\right]^{n-m_{2}^{*}}}{\left[\frac{\Gamma(c+d)}{\Gamma(c) \Gamma(d)}\right]^{m_{2}-m_{1}}\left[\frac{\Gamma(e+f)}{\Gamma(e) \Gamma(f)}\right]^{n-m_{2}}} \\
\quad \times \frac{\prod_{i=m_{1}+1}^{m_{2}^{*}} y_{i}^{c-1}\left(1-y_{i}\right)^{d-1} \prod_{i=m_{2}^{*}+1}^{n} y_{i}^{e-1}\left(1-y_{i}\right)^{f-1}}{\prod_{i=m_{1}+1}^{m_{2}} y_{i}^{c-1}\left(1-y_{i}\right)^{d-1} \prod_{i=m_{2}+1}^{n} y_{i}^{e-1}\left(1-y_{i}\right)^{f-1}}
\end{gathered}
$$

